\title{
The Contribution of Acute Toxicity in Animals to Occupational Exposure Limits of Chemical Substances
}

\author{
Megumi SUDA, Hiroshi TSURUTA and Takeshi HONMA* \\ National Institute of Industrial Health (Ministry of Labour), Nagao 6-21-1, Tama-ku, Kawasaki 214-8585, Japan
}

Received September 25, 1998 and accepted November 29, 1998

\begin{abstract}
The correlations of lethal doses of various industrial chemicals for rats and mice with occupational exposure limit values were investigated. $50 \%$ lethal dose $\left({ }^{2} D_{50}\right)$ values obtained by oral (p.o.) and intraperitoneal (i.p.) injection and $50 \%$ lethal concentration $\left(\mathbf{L C}_{50}\right)$ values obtained by inhalation exposure were collected from Registry of Toxic Effects of Chemical Substances (RTECS). Threshold Limit Value (Time-Weighted Average) (TLVs-TWA) and Threshold Limit Value (Short Term Exposure Limit) (TLVs-STEL) recommended by American Conference of Governmental Industrial Hygienists (ACGIH) were used as exposure limits. TLVs-TWA or TLVs-STEL and LD or $\mathrm{LC}_{50}$ values obtained for the rats were plotted on logarithmic scales on the ordinate and abscissa, respectively. High correlations were obtained between these parameters. The order of correlations

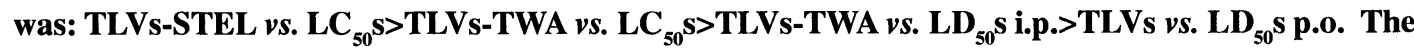
same calculations for the relationship between TLVs and lethal doses in mice were also performed. The order of the three types of correlations was same as that of the rats; however, correlation coefficients for TLVs-STEL $v s$. $\mathrm{LC}_{50} \mathrm{~S}$ and for TLVs-TWA $v s$. $\mathbf{L C}_{50} \mathrm{~s}$ obtained in mice were smaller than those in rats. TLVs-TWA are, therefore, well correlated with $L_{50}$ values rather than $L_{50}$ values, particularly with those in rats. High correlations between TLVs-STEL $v s$. $L C_{50} \mathrm{~s}$ were also obtained, as had been expected before calculation. The equation: TLV-TWA $=10^{\mathrm{b}} \times\left(\mathrm{LC}_{50}\right)^{\mathrm{a}}$ can be obtained from these plottings, where the values $a$ and $b$ are taken from each linear regression line. TLV-TWA for each chemical can be calculated by using $L_{50}$ and the equation. The upper and lower $95 \%$ confidence limits for calculated TLV-TWA were TLV-TWA (calculated from $L_{50}$ ) $\times 22.9$ and TLV-TWA (calculated)/22.9, respectively, where $\mathrm{LC}_{50}$ for rats expressed in ppm $\times \mathrm{hr}$ was used.
\end{abstract}

Key words: TLV-TWA, TLV-STEL, $\mathrm{LD}_{50}, \mathrm{LC}_{50}$, Correlation coefficients, Rats, Mice

\section{Introduction}

To determine exposure limit values of industrial chemicals, different kinds of data must be reviewed ${ }^{1,2)}$. Epidemiology and animal experiments are major sources of such data. Acute, subacute, and chronic toxicity tests are involved in animal experiments. Although acute toxicity is considered in the setting of short-term exposure limits, acute toxicity data is usually considered to be a small part of a large body of data that is available for the determination of exposure

\footnotetext{
*To whom correspondence should be addressed.
}

limits of chemical substances. This tendency occurs because long-term exposure effects, such as carcinogenicity, are frequently considered to be more important ${ }^{3}$. Nevertheless, acute toxicity data should not be ignored, because it is in many cases influential in setting short-term exposure limits. Acute toxicity is estimated primarily in the process of the accumulation of data, and it is referred to in further steps such as subchronic and chronic toxicity experiments. While data on carcinogenicity, neurotoxicity, and so on are very important, acquiring this data is very expensive and timeconsuming. On the other hand, acute toxicity data such as $50 \%$ lethal dose $\left(\mathrm{LD}_{50}\right)$ is relatively easy to obtain. For this 
reason, we should use acute toxicity data to its fullest potential. Provided that it is possible to estimate approximate values of exposure limits using acute toxicity data, it is beneficial for at least temporal values in the setting of exposure limits. As a part of such trials, we calculated the correlations between Threshold Limit Values (TimeWeighted Average) (TLVs-TWA) for workers recommended by the American Conference of Governmental Industrial Hygienists (ACGIH), and $\mathrm{LD}_{50}$ or $50 \%$ lethal concentration $\left(\mathrm{LC}_{50}\right)$ values obtained in animals. Furthermore, we calculated correlations between TLVs-STEL (short-term exposure limit) and lethal doses. These TLVs were adopted because they are constantly referred to as occupational exposure limits worldwide. $\mathrm{LD}_{50}$ values in oral and intraperitoneal administration and $\mathrm{LC}_{50}$ values in inhalation exposures in animals were obtained from the Registry of Toxic Effects of Chemical Substances (RTECS) ${ }^{4)}$, because we needed a large number of lethal doses to perform statistical treatment. As far as we know, statistical treatments have not heretofore been done concerning correlations between TLVs and $\mathrm{LD}_{50}$ or $\mathrm{LC}_{50}$ values. In this paper, we described the results of statistical calculations of such correlations.

\section{Materials and Methods}

We selected compounds for which $\mathrm{LD}_{50}$ values for oral or intraperitoneal administration $\left(\mathrm{LD}_{50}\right.$ p.o. or $\mathrm{LD}_{50}$ i.p.) were given in the 1995 RTECS. $\mathrm{LD}_{50}$ s for other injection routes were not utilized because the sample sizes in subcutaneous or intravenous administration were small. Compounds for which the $\mathrm{LC}_{50}$ values and exposure time were described in the RTECS were also selected. The animal species tested were limited to rats and mice because the sample sizes of other animals were too small. All compounds for which TLVs were given in 1995 are included in this study. However, compounds that were solid at room temperature were excluded. Statistical treatment of TLVs-TWA, TLVs-STEL, $\mathrm{LD}_{50} \mathrm{~s}$, and $\mathrm{LC}_{50} \mathrm{~s}$ with the calculation of the correlation coefficients and the linear regressions was performed on a PC using SPSS 6.1 for Windows software which was purchased from SPSS Japan, Inc.

\section{Results}

\section{Correlation coefficients}

TLVs-TWA and $\mathrm{LD}_{50}$ or $\mathrm{LC}_{50}$ values in rats were plotted for many chemicals. In Fig. 1, TLVs-TWA and the $L D_{50}$ p.o. values in rats were plotted for 211 chemicals on the ordinate and abscissa, respectively. A logarithmic scale was used for both the ordinate and abscissa. In Fig. $1 \mathrm{~A}, \mathrm{LD}_{50} \mathrm{~s}$ are expressed in $\mathrm{mg} / \mathrm{kg}$, because all of the $\mathrm{LD}_{50}$ data in RTECS was given as $\mathrm{mg} / \mathrm{kg}$ or $\mu \mathrm{g} / \mathrm{kg}$. The correlation coefficient between these two parameters was calculated to be $r=0.616$ $(n=211)$ (Table 1). In Fig. 1B, the units for $L_{50}$ were converted from $\mathrm{mg} / \mathrm{kg}$ to $\mathrm{mmol} / \mathrm{kg}$. From the relationship in Fig. 1B, $r=0.691$ was obtained (Table 1). As the differences in these coefficients shows, the correlation was improved by converting the units for $\mathrm{LD}_{50}$ from $\mathrm{mg} / \mathrm{kg}$ to $\mathrm{mmol} / \mathrm{kg}$.

The same procedure was applied for the calculation of the correlation coefficients between TLVs-TWA and $\mathrm{LD}_{50}$ i.p. values in rats (Fig. 2). In Fig. $2 A, L_{50} s$ were expressed in $\mathrm{mg} / \mathrm{kg}$. The correlation coefficient between these two parameters was calculated to be $r=0.626(n=96)$ (Table 1). In Fig. 2B, the units for $\mathrm{LD}_{50}$ were converted from $\mathrm{mg} / \mathrm{kg}$ to

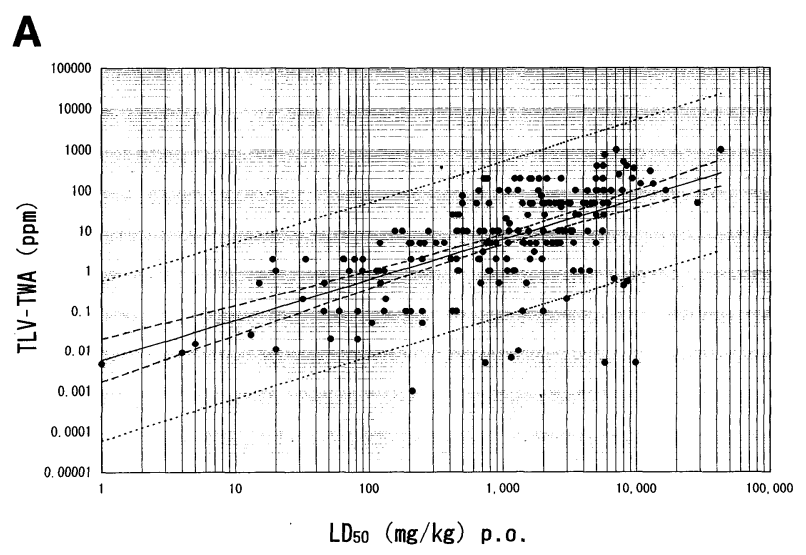

B

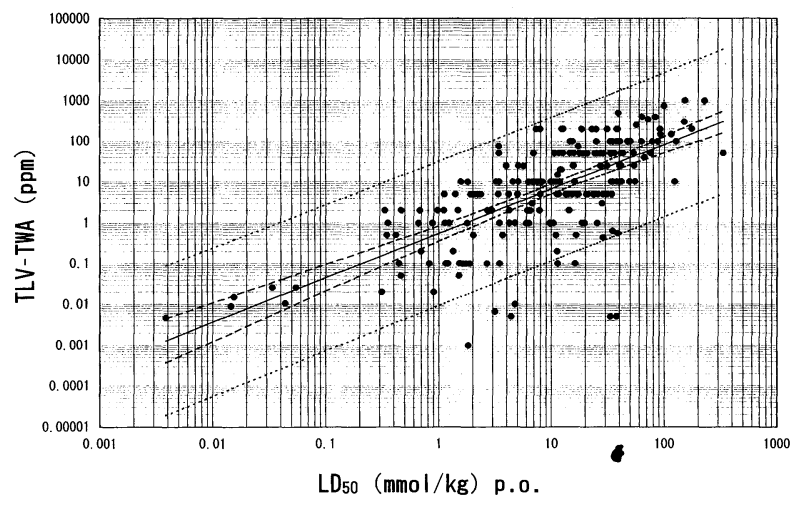

Fig. 1. Correlation of TLVs-TWA and $L D_{50}$ values in oral administration in rats.

Units of ordinate and abscissa are as follows: ppm and $\mathrm{mg} / \mathrm{kg}$ in Fig. 1A (upper), ppm and mmol/kg in Fig. 1B (lower). Regression line (solid line), 95\% confidence limits for the regression line (broken), and 95\% confidence limits for individual values (dotted) were calculated. 
Table 1. Correlation coefficients between TLVs (ACGIH) and $L_{50}$ values in oral or intraperitoneal administration or $\mathrm{LC}_{50} \mathrm{~s}$ in inhalation exposure in rats and mice.

\begin{tabular}{|c|c|c|c|c|c|c|c|}
\hline & & $\mathrm{N}$ & $\mathbf{r}$ & $y=10^{b} x^{a}$ & $\mathbf{t}_{0.05}$ & $\mathbf{s}$ & $10^{t_{0.05} \cdot s}$ \\
\hline \multirow[t]{8}{*}{ Rats } & TLVs-TWA (ppm) - LD ${ }_{50}(\mathrm{mg} / \mathrm{kg})$ p.o. & 211 & 0.616 & $y=0.00582 x^{1.01}$ & 1.971 & 0.970 & 81.9 \\
\hline & TLVs-TWA $(\mathrm{ppm})-\mathrm{LD}_{50}(\mathrm{mmol} / \mathrm{kg})$ p.o. & 211 & 0.691 & $\mathrm{y}=0.550 \mathrm{x}^{1.09}$ & 1.971 & 0.891 & 57.1 \\
\hline & TLVs-TWA (ppm) - LD ${ }_{50}(\mathrm{mg} / \mathrm{kg})$ i.p. & 96 & 0.626 & $y=0.0209 x^{0.899}$ & 1.986 & 0.933 & 71.2 \\
\hline & TLVs-TWA (ppm) $-\mathrm{LD}_{50}(\mathrm{mmol} / \mathrm{kg})$ i.p. & 96 & 0.717 & $\mathrm{y}=1.21 \mathrm{x}^{0.990}$ & 1.986 & 0.834 & 45.2 \\
\hline & TLVs-TWA (ppm) - LC ${ }_{50}(\mathrm{ppm}) \mathrm{inh}$ & 113 & 0.859 & $y=0.00440 x^{1.02}$ & 1.982 & 0.689 & 23.2 \\
\hline & TLVs-TWA $(\mathrm{ppm})-\mathrm{LC}_{50}(\mathrm{ppm} \times \mathrm{hr})$ inh. & 113 & 0.861 & $y=0.00146 x^{1.00}$ & 1.982 & 0.686 & 22.9 \\
\hline & TLVs-STEL(ppm) - LC $_{50}(\mathrm{ppm})$ inh. & 37 & 0.867 & $y=0.03090 x^{0.898}$ & 2.030 & 0.576 & 14.8 \\
\hline & TLVs-STEL $(\mathrm{ppm})-\mathrm{LC}_{50}(\mathrm{ppm} \times \mathrm{hr})$ inh. & 37 & 0.912 & $y=0.01072 x^{0.888}$ & 2.030 & 0.473 & 9.13 \\
\hline \multirow[t]{8}{*}{ Mice } & TLVs-TWA (ppm) - LD ${ }_{50}(\mathrm{mg} / \mathrm{kg})$ p.o. & 152 & 0.603 & $y=0.00569 x^{1.01}$ & 1.976 & 0.946 & 74.1 \\
\hline & TLVs-TWA $(\mathrm{ppm})-\mathrm{LD}_{50}(\mathrm{mmol} / \mathrm{kg})$ p.o. & 152 & 0.690 & $y=0.540 x^{1.08}$ & 1.976 & 0.858 & 49.7 \\
\hline & TLVs-TWA $(\mathrm{ppm})-\mathrm{LD}_{50}(\mathrm{mg} / \mathrm{kg})$ i.p. & 132 & 0.617 & $\mathrm{y}=0.0220 \mathrm{x}^{0.970}$ & 1.978 & 0.939 & 72.2 \\
\hline & TLVs-TWA (ppm) $-\mathrm{LD}_{50}(\mathrm{mmol} / \mathrm{kg})$ i.p. & 132 & 0.699 & $y=1.79 x^{1.04}$ & 1.978 & 0.853 & 48.8 \\
\hline & TLVs-TWA (ppm) - LC ${ }_{50}(\mathrm{ppm})$ inh. & 84 & 0.818 & $y=0.00440 x^{1.02}$ & 1.989 & 0.746 & 30.4 \\
\hline & TLVs-TWA $(\mathrm{ppm})-\mathrm{LC}_{50}(\mathrm{ppm} \times \mathrm{hr})$ inh. & 84 & 0.797 & $y=0.00146 x^{1.00}$ & 1.989 & 0.782 & 36.0 \\
\hline & TLVs-STEL(ppm) - LC $_{50}(\mathrm{ppm})$ inh. & 24 & 0.804 & $y=0.01380 x^{1.06}$ & 2.074 & 0.649 & 22.2 \\
\hline & TLVs-STEL $(\mathrm{ppm})-\mathrm{LC}_{50}(\mathrm{ppm} \times \mathrm{hr})$ inh. & 24 & 0.819 & $y=0.00209 x^{1.18}$ & 2.074 & 0.627 & 19.9 \\
\hline
\end{tabular}

$\mathrm{mmol} / \mathrm{kg}$, and $\mathrm{r}=0.717$ was obtained (Table 1 ). As these two parameters show, the correlation coefficient in Fig. 2B was greater than that in Fig. 2A. Also in this case, the correlation was improved by converting the units for $\mathrm{LD}_{50}$ from $\mathrm{mg} / \mathrm{kg}$ to $\mathrm{mmol} / \mathrm{kg}$.

In Fig. 3, TLVs-TWA and the $\mathrm{LC}_{50}$ values for inhalation exposure in rats were plotted. In Fig. $3 \mathrm{~A}, \mathrm{LC}_{50} \mathrm{~s}$ were expressed in ppm. Exposure duration in $\mathrm{LC}_{50}$ data obtained from RTECS was not considered. The correlation coefficient between these two parameters was calculated to be $r=0.859$ $(\mathrm{n}=113)$ (Table 1). In Fig. 3B, ppm $\times$ hr (multiplication of $\mathrm{LC}_{50}$ in ppm and exposure duration in hrs obtained from RTECS) was used instead of ppm as the units for $\mathrm{LC}_{50}$. From the relationship shown in Fig. 3B, $r=0.861$ was obtained (Table 1). As Table 1 shows, the correlation obtained by using ppm $\times \mathrm{hr}$ remained almost the same as that obtained by using ppm.

Figs. 4A and 4B show the correlations between TLVsSTEL and $\mathrm{LC}_{50} \mathrm{~s}$ in rats. The number of compounds which were given TLVs-STEL $(\mathrm{N}=37)$ was not so great as the number of TLVs-TWA. In Fig. $4 \mathrm{~A}, \mathrm{LC}_{50} \mathrm{~s}$ are expressed in $\mathrm{ppm}$. The correlation coefficient in this correlation was 0.867 (Table 1). This value was almost the same as values found in correlations between TLVs-TWA and $\mathrm{LC}_{50} \mathrm{~s}(\mathrm{ppm})$. In Fig. 4B, ppm $\times \mathrm{hr}$ was used instead of ppm as the unit for $\mathrm{LC}_{50}$ s. The relationship in Fig. $4 \mathrm{~B}$ gave the correlation coefficient 0.912 , shown in Table 1 . As for the correlation between TLVs-STEL and $\mathrm{LC}_{50}$, the use of $\mathrm{ppm} \times \mathrm{hr}$ rather

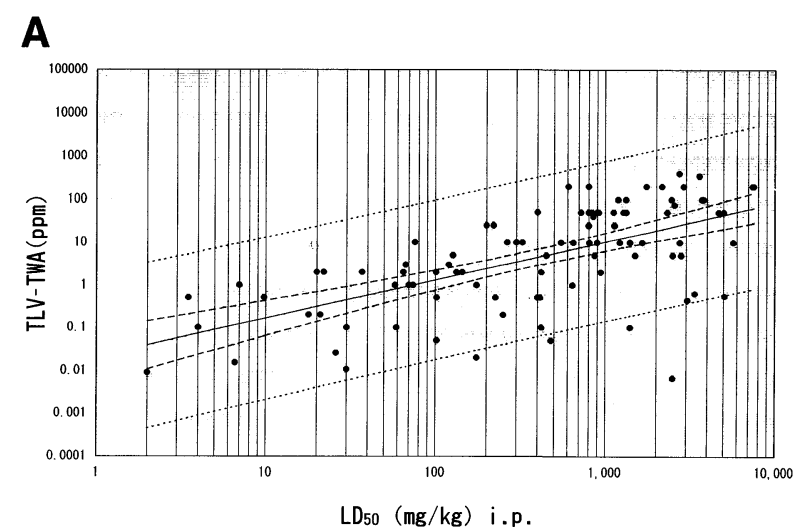

B

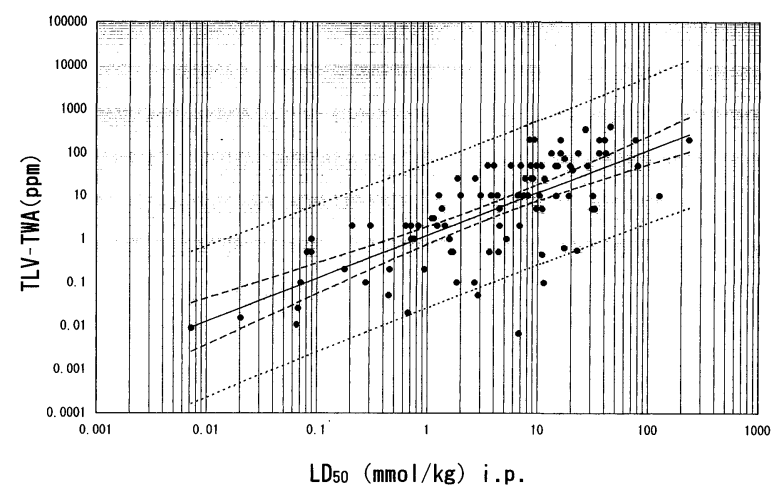

Fig. 2. Correlation of TLVs-TWA and $\mathrm{LD}_{50}$ values in intraperitoneal administration in rats.

Units of ordinate and abscissa are as follows: ppm and $\mathrm{mg} / \mathrm{kg}$ in Fig. 2A (upper), ppm and mmol/kg in Fig. $2 \mathrm{~B}$ (lower). 

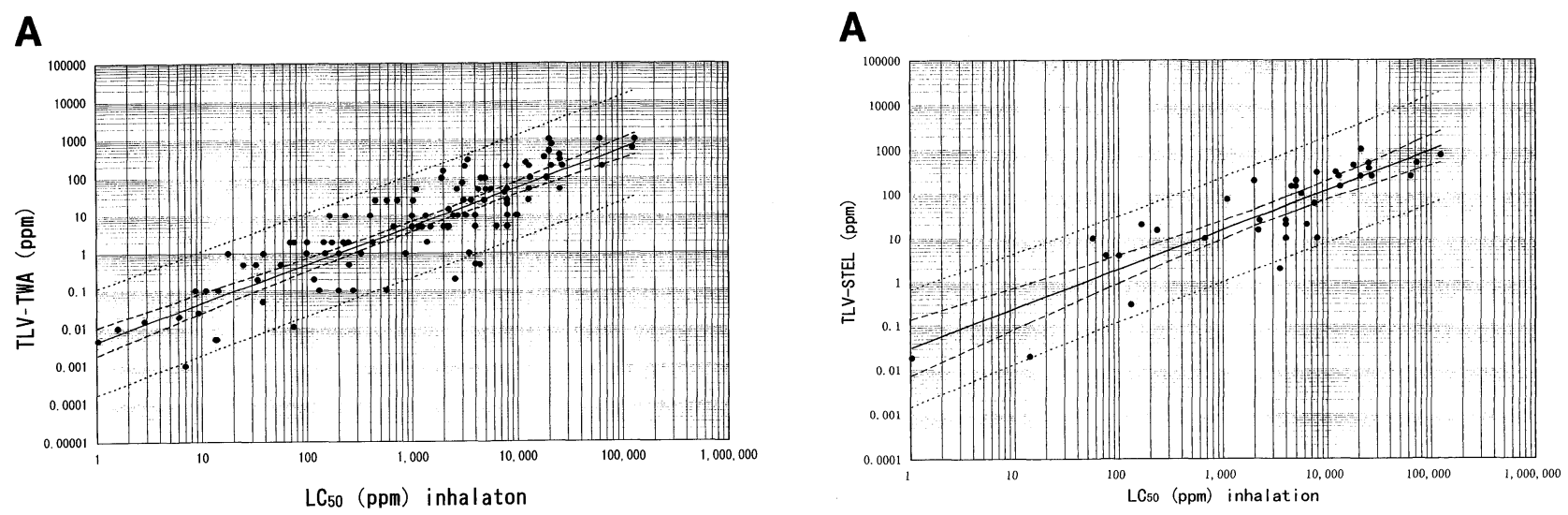

B

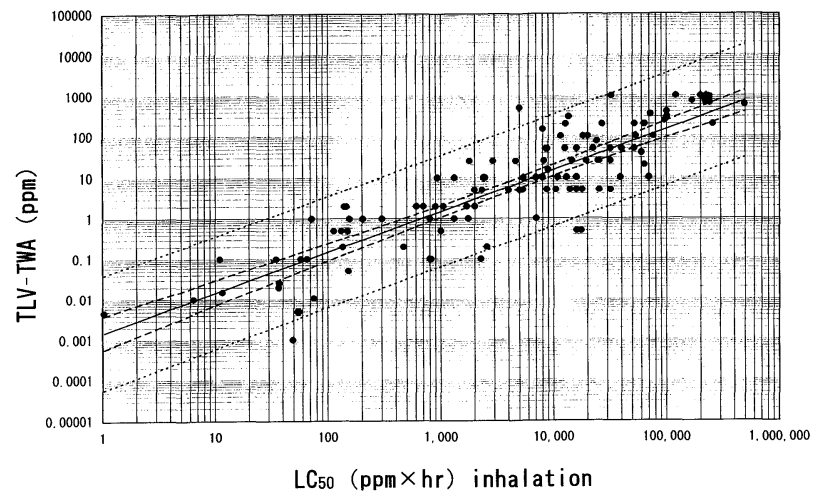

B

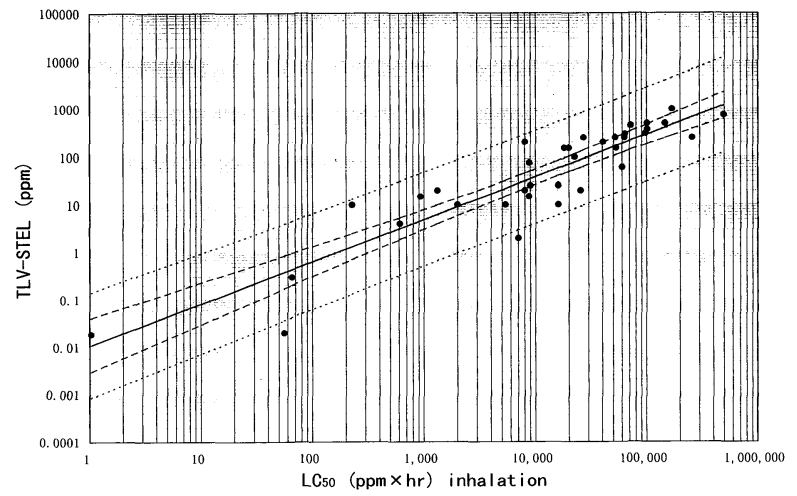

Fig. 3. Correlation of TLVs-TWA and $\mathrm{LC}_{50}$ values in inhalation exposure in rats.

Units of ordinate and abscissa are as follows: ppm and ppm in Fig. 3A (upper), ppm and ppm $\times$ hr in Fig. 3B (lower).

than ppm clearly improved the correlation.

TLVs and $\mathrm{LD}_{50}$ p.o., $\mathrm{LD}_{50}$ i.p., or $\mathrm{LC}_{50}$ values obtained in mice, were plotted in the same way as for rats. Correlation coefficients are summarized in Table 1.

In correlation between TLVs-TWA and $\mathrm{LD}_{50}$ p.o. values in mice $(\mathrm{n}=152)$, an improved correlation was obtained by converting the unit $\mathrm{mg} / \mathrm{kg}(\mathrm{r}=0.603)$ to $\mathrm{mmol} / \mathrm{kg}(\mathrm{r}=0.690)$. Also, the correlation between TLVs-TWA and $\mathrm{LD}_{50}$ i.p. in mice $(\mathrm{n}=132)$ was improved by converting the unit for $\mathrm{LD}_{50}$ from $\mathrm{mg} / \mathrm{kg}(\mathrm{r}=0.617)$ to $\mathrm{mmol} / \mathrm{kg}(\mathrm{r}=0.699)$. However, there was no improvement in the correlation between TLVs-TWA and $\mathrm{LC}_{50}$ values $(\mathrm{n}=84)$ with conversion of the unit ppm $(\mathrm{r}=0.818)$ to $\mathrm{ppm} \times \mathrm{hr}(\mathrm{r}=0.797)$. In the correlations between TLVs-STEL and $\mathrm{LC}_{50} \mathrm{~s}$ in mice, a small number of compounds was given TLVs-STEL $(\mathrm{N}=24) . \quad \mathrm{LC}_{50} \mathrm{~s}$ were expressed in $\mathrm{ppm}$ and in $\mathrm{ppm} \times \mathrm{hr}$, and the correlation coefficients in these cases were 0.804 and 0.819 , respectively (Table 1 ). These values were similar to values given in correlations

Fig. 4. Correlation of TLVs-STEL and $\mathrm{LC}_{50}$ values in inhalation exposure in rats.

Units of ordinate and abscissa are as follows: ppm and ppm in Fig. 4A (upper), ppm and ppm $\times$ hr in Fig. 4B (lower).

between TLVs-TWA and $\mathrm{LC}_{50} \mathrm{~s}$.

\section{Equations to derive TLVs from $L D_{50}$ s or $L C_{50} s$}

For all linear regressions, the $95 \%$ confidence limits for linear regression and the $95 \%$ confidence limits for the individual values were calculated. Each confidence limit obtained in correlations between TLVs and $\mathrm{LD}_{50} \mathrm{~s}$ or $\mathrm{LC}_{50} \mathrm{~s}$ in rats is shown in the figures.

For each linear regression, the following equation was used:

$$
\log _{10} \mathrm{Y}=\mathrm{a} \cdot \log _{10} \mathrm{X}+\mathrm{b}
$$

From equation (A), the following equation (B) can be derived.

$$
\mathrm{Y}=\mathrm{X}^{\mathrm{a}} \cdot 10^{\mathrm{b}}
$$

Parameters $\mathrm{a}$ and $\mathrm{b}$ were calculated from the linear regression. All results of the calculations are summarized in Table 1, as $10^{\mathrm{b}}$ and a values in the equation (B).

From each plotting, $\mathrm{t}_{0.05}, \mathrm{~s}$, and $10^{\mathrm{t}_{0.05} \cdot \mathrm{s}}$ values were 
calculated and are summarized in Table 1 . These values imply that $95 \%$ of all chemicals in the plotting are found between the upper limit, $\mathrm{y} \times 10^{\mathrm{t}_{0.05}} \mathrm{~s}^{\mathrm{s}}$, and the lower limit, $\mathrm{y} /$ $10^{\mathrm{t}_{0.05} \cdot \mathrm{s}}$. In the correlation between TLVs-TWA and $\mathrm{LC}_{50} \mathrm{~s}$ in rats, TLV-TWA can be derived from $\mathrm{LC}_{50}(\mathrm{ppm} \times \mathrm{hr})$ according to the equation $\mathrm{y}=0.00146 \mathrm{x}^{1.00}$. When $\mathrm{LC}_{50}$ (ppm $\times \mathrm{hr}$ ) is 685 , TLV-TWA can be obtained as $1 \mathrm{ppm}$. In this case, $10^{t_{0.05} \cdot s}$ was calculated as 22.9. From this value, 22.9 and 0.0437 are derived as upper and lower limits, respectively, of $95 \%$ confidence limit values.

\section{Discussion}

With a progress of toxicological sciences, a great amount of toxicity data has been accumulated in such toxicity fields as carcinogenicity, neurotoxicity, immunotoxicity, reproductive toxicity, and so on. As a result, the emphasis on acute toxicity seems to have diminished somewhat. However, acute toxicity must be estimated at the beginning of toxicity testings because lethal doses in acute toxicity testings are indispensable to the whole process of toxicity experiments. In such fields as carcinogenicity, neurotoxicity, and so forth, more complex and specialized techniques have been required, and the cost of manpower, apparatus, and other needs for toxicity testings is increasing every year. Acute toxicity data, however, is relatively easy to obtain at a lower cost. Therefore, the significance of acute toxicity data must be considered in determination of exposure limit values. Also to set occupational exposure limits, acute toxicity data must be maximally utilized.

In this study, we calculated the correlations between TLVsTWA or TLVs-STEL and $\mathrm{LD}_{50}$ or $\mathrm{LC}_{50}$ values and obtained high correlations. In our previous report ${ }^{5,6}$, we clarified that good correlations exist between $\mathrm{LC}_{50} \mathrm{~s}$ obtained in inhalation exposures and $\mathrm{LD}_{50} \mathrm{~s}$ obtained in oral or intraperitoneal administrations ${ }^{6}$. In those calculations, the degree of correlations was improved by converting the units from $\mathrm{mg} / \mathrm{kg}$ to $\mathrm{mmol} / \mathrm{kg}$ for $\mathrm{LD}_{50} \mathrm{~s}$ both in rats and in mice. By the same conversion of units, similar improvement was observed in our present calculations clarifying high correlations between TLVs and $\mathrm{LD}_{50} \mathrm{~s}$ or $\mathrm{LC}_{50} \mathrm{~s}$. This is probably because ppm is used as the unit for TLVs. The unit ppm is based on the number of molecules, and not on the weight of chemicals, which exist in a specific volume of air. The doses expressed as $\mathrm{mmol} / \mathrm{kg}$ are also based on the number of molecules. Higher correlations had been expected between TLVs-TWA and $\mathrm{LC}_{50}$ values rather than between TLVs-TWA and $\mathrm{LD}_{50}$ values, because TLVs-TWA values are based on inhalation exposure situations. The actual results of calculations were strongly consistent with the expectations.

Correlations between TLVs-TWA and $\mathrm{LC}_{50} \mathrm{~s}$ were not improved by converting the units of $\mathrm{LC}_{50}$ from ppm to $\mathrm{ppm}$ $x \mathrm{hr}$ in both rats and mice. This result was unexpected because toxicity appears to depend on both exposure concentration and exposure time. The reason for this result is not clear. On the other hand, the correlation between TLVs-STEL and $\mathrm{LC}_{50}$ in rats was clearly improved by converting the units of $\mathrm{LC}_{50}$ from ppm to $\mathrm{ppm} \times \mathrm{hr}$. The same unit conversion did not improve the correlation between TLVs-STEL and $\mathrm{LC}_{50}$ in mice. These differences may suggest that rats rather than mice are suitable as experimental animals.

The correlations between TLVs-TWA and $\mathrm{LD}_{50}$ values in rats were almost the same as those in mice. However, the correlations between TLVs-TWA and $\mathrm{LC}_{50}$ values in rats were higher than those in mice. There exist many differences between the body sizes, nasal cavities, trachea, bronchi, and lungs of rats and mice, affecting the absorption efficiency of inhaled chemicals. These differences may have increased the efficiency of chemical absorption into body. Also such factors must be considered as the differences in structure, lobulation, and terminal airways, as well as in function, posture, chest wall compliance, and mechanical reflexes. Differences in dermal absorption, lung absorption coefficient, breathing frequency, and respiratory volume also exist between rats and mice. These differences may have affected the correlations between TLVs-TWA and $\mathrm{LC}_{50}$ values. High correlations between TLVs-TWA and $\mathrm{LC}_{50} \mathrm{~s}$ in rats suggest that rats are more suitable than mice for considering occupational exposure limit values from $\mathrm{LC}_{50}$ values in animals.

In the plotting of TLVs-TWA and $\mathrm{LD}_{50}$ p.o. values in rats (Figs. 1A \& 1B), 6 chemicals were located far from the lower limit of the $95 \%$ confidence limits for individual values (dotted line). These chemicals were bis (chloromethyl) ether, toluene-2,4-diisocyanate, hexamethylene diisocyanate, trio-cresyl phosphate, hexachlorocyclopentadiene, and methylenebiscyclohexyl cyanate. These chemicals are known as potent carcinogens, immunotoxicants, and so forth. In the plotting of TLVs-TWA and $\mathrm{LD}_{50}$ i.p. values in rats (Figs. 2A \& 2B), only one chemical, tri-o-cresyl phosphate, was far from the lower limit of the $95 \%$ confidence limits for individual values. In the plotting of TLVs-TWA and $\mathrm{LC}_{50}$ values in rats (Figs. 3A \& 3B), all chemicals were located either between the upper and lower limits of these confidence limits or very close to these limits. The degree of deviation 
of each chemical from the regression line can be seen from $10^{t_{0.05} \cdot s}$ values (Table 1). The order of the degree was as follows: TLVs-STEL $v s$. LC $_{50}<$ TLVs-TWA $v s$. LC $_{50}<$ TLVsTWA vs. $\mathrm{LD}_{50}$ i.p. $<$ TLVs-TWA vs. $\mathrm{LD}_{50}$ p.o. This order was strongly consistent with that obtained by the differences in correlation coefficient values.

In the correlation between TLVs-TWA and $\mathrm{LD}_{50}(\mathrm{mg} / \mathrm{kg})$ p.o. in rats, the $10^{t_{0.05} \cdot s}$ value was 81.9. When TLVs-TWA are calculated from $\mathrm{LD}_{50}(\mathrm{mg} / \mathrm{kg})$ in rats by the equation (B), 95\% confidence limits for calculated TLVs-TWA are obtained as TLV-TWA (calculated) $\times 81.9$ and TLV-TWA (calculated)/81.9. On the other hand, the value of 22.9 was given as $10^{\mathrm{t} .05^{\circ}}$ s in the correlation between TLVs-TWA and $\mathrm{LC}_{50}(\mathrm{ppm} \times \mathrm{hr})$ in rats. When TLVs-TWA are obtained from $\mathrm{LC}_{50}(\mathrm{ppm} \times \mathrm{hr})$ in rats by the equation $(\mathrm{B})$, most of actual TLVs-TWA are located between the TLV-TWA (calculated) $\times 22.9$ and TLV-TWA (calculated)/22.9 values. This range was not so great as that obtained from correlations between TLVs-TWA and $\mathrm{LD}_{50} \mathrm{~s}$. This result means that lethal doses, particularly $\mathrm{LC}_{50}(\mathrm{ppm} \times \mathrm{hr})$ values obtained in rats, can be good indicators for setting TLVs-TWA.

TLVs-STEL are set usually with consideration to the acute effects of chemicals ${ }^{3}$. Although the acute effects in these cases do not always imply $\mathrm{LD}_{50}$ or $\mathrm{LC}_{50}$ values, high correlations between TLVs-STEL and $\mathrm{LD}_{50}$ or $\mathrm{LC}_{50}$ values were expected. In our calculations, high correlations were obtained between these values and the ranges of confidence limits for these regression lines were very small (Table 1).

We have obtained high correlations between TLVs-TWA and $\mathrm{LC}_{50}$ or $\mathrm{LD}_{50}$ values, and these correlations were higher than those we expected before calculations. As TLVs-TWA are usually determined by utilizing data of the chronic effects of chemicals, such high correlations had not been expected. It should be recognized that data obtained in acute toxicity testings is important not only in the determination of acute exposure limits as TLVs-STEL but also in the setting of TLVsTWA. We should take more advantage of data already presented in the literature on the topic.

Part of this paper was presented at the International Congress of Toxicology-VII, July 2-6, 1995, Seattle, Washington.

\section{References}

1) Dourson ML, Stara JF (1983) Regulatory history and experimental support of uncertainty (safety) factors. Regul Toxicol Pharm 3, 224-38.

2) Doull J (1993) Extrapolation of animal results to man. J Toxicol Sci 18, 69-71.

3) Environmental Health Criteria 170. Assessing Human Health Risks of Chemicals: Derivation of Guidance Values for Health-based Exposure Limits. IPCS, WHO, Geneva 1994.

4) Registry of Toxic Effects of Chemical Substances (RTECS) 1995, NIOSH, Cincinnati, Ohio.

5) Kanada M, Honma $T$ (1993) Correlation of toxicity data between administration and inhalation of organic solvents. Annual Report of National Institute of Industrial Health - 1992. $\mathrm{p} 20$.

6) Honma T, Suda M (1998) Correlation of lethal doses of industrial chemicals between oral or intraperitoneal administration and inhalation exposure. Ind Health 36, 273-81. 